\title{
O Ensino da Leitura no Discurso Pedagógico Contemporâneo
}

\begin{abstract}
Raquel Goulart Barreto'
Glaucia Campos Guimarães'

'Universidade do Estado do Rio de Janeiro (UERJ), Rio de Janeiro/RJ - Brasil

RESUMO - O Ensino da Leitura no Discurso Pedagógico Contemporâneo. Fundado na análise de uma proposta de trabalho com leitura em pesquisa participante, este artigo visa a discutir leitura e produção textual na escola hoje. Está dividido em quatro seções que abordam: (1) o discurso pedagógico como arena de luta por hegemonia, envolvendo os modos pelos quais as tecnologias da informação e da comunicação tendem a ser recontextualizadas nas práticas escolares; (2) meios de buscar a aproximação do movimento dos sentidos através do ensino da leitura; (3) resultados da pesquisa desenvolvida em uma escola pública, visando a fornecer subsídios para outros movimentos de recontextualização; e (4) dimensões do trabalho docente, com ênfase em leitura e produção textual.

Palavras-chave: Ensino. Leitura. Produção Textual. Discurso Pedagógico.

ABSTRACT - Teaching Reading in Contemporary Pedagogic Discourse. Based on the analysis of an action research on reading, this paper aims at discussing reading and text production at schools nowadays. It is divided into four sections, as follows: (1) pedagogic discourse as the arena for struggling for hegemony, involving the ways information and communication technologies are to be recontextualized in school practices; (2) means to approach meaning production in teaching reading; (3) results of the action research developed in a public school, so as to provide the basis for other recontextualization movements; and (4) dimensions of teachers' work, especially as far as reading and text production are concerned.

Keywords: Teaching. Reading. Text Production. Pedagogical Discourse.
\end{abstract}

Educação \& Realidade, Porto Alegre, v. 40, n. 2, p. 573-590, abr./jun. 2015. 


\section{Caracterização da Abordagem}

De Comenius, no século XVII, aos dias atuais, pensar a prática pedagógica tem suscitado questões referentes ao quê e como fazer, estas últimas muitas vezes enfatizadas a ponto de constituir tendência tecnicista hegemônica, especialmente a partir dos anos 1970. Entretanto, as referidas questões têm sido reconfiguradas a ponto de fazer com que a obra fundadora de Comenius, publicada em 1649, tenha por título Didáctica Magna (2006), enquanto abordagens mais recentes, voltadas para a formação de professores, se articulam em termos de Alternativas do Ensino de Didática, como no trabalho organizado por André e Oliveira (1996). Nos discursos materializados nos títulos citados, é marcante o deslocamento de princípios e regras supostamente universais, no sentido de aplicáveis a quaisquer situações, para a produção de propostas plurais, historicamente situadas, no sentido de ancoradas nas condições concretas de realização do trabalho docente.

Obviamente, a ruptura com a suposta ausência de dúvidas e o reconhecimento do papel mediador da pesquisa na formulação das propostas de ensino implicam grandes desafios no contexto da formação de professores. É mais demorado e caro conjugar o ensino da pesquisa e a pesquisa do ensino como eixo da formação. Daí o movimento oposto, que se afasta da formação propriamente dita e promove o esvaziamento progressivo do trabalho docente, até compatível com uma indagação extraída da obra de Comenius (2006, p. 203): "Quem não sabe, porém, que mesmo as coisas longas podem ser abreviadas e as trabalhosas, resumidas?"

Em processo que remete a aligeiramento/esvaziamento da formação e do trabalho docente, tomando por base a análise do Estado do Conhecimento em Educação e Tecnologia (1996-2002) ${ }^{1}$, publicado pelo INEP em 2006, é delineado o movimento da sua incorporação educacional como estratégia de substituição tecnológica, em contexto marcado por uma quebra de unidade: o afastamento progressivo das questões relativas ao ensino, na tendência a celebrar uma espécie de (auto)aprendizagem (Barreto, 2012).

Em outras palavras, apontando na direção contrária às alternativas de ensino, ao invés de agregar valor às práticas pedagógicas, as tecnologias da informação e da comunicação (TIC) têm favorecido a circulação de materiais prontos, apagando as diversas dimensões de ensinar-aprender, em nome da proliferação de objetos de aprendizagem, armazenados em bancos projetados para contê-los².

Na configuração da proposta, a formação e o trabalho docente podem ser reduzidos ao treinamento das habilidades desejáveis ao gerenciamento de materiais de ensino, ora relexicalizados como objetos de aprendizagem, que, traduzindo os parâmetros curriculares, favoreçam um bom desempenho na avaliação das competências estabelecidas. 
Neste ponto, parece oportuno esclarecer que não se trata de rejeitar $a$ priori o armazenamento de sequências de ensino, mas a sua condição de modelos supostamente aplicáveis a quaisquer situações. Cabe acrescentar que, nos bancos $^{3}$, a caracterização dos referidos objetos destaca, invariavelmente, a possibilidade da sua reutilização. No segundo exemplo listado em rodapé (Programa Conexão Professor), a perspectiva neotecnicista, que alia o reducionismo à sofisticação tecnológica, é marcada na introdução aos objetos de aprendizagem, grafada em maiúsculas: "SAIBA COMO TRABALHÁ-LOS EM SALA DE AULA"4.

De certo modo, a formulação neotecnicista ilustra o deslocamento em relação ao que se pode chamar de Didática tradicional: das grandes prescrições aos materiais prontos, acompanhados de instruções de uso. Neste percurso, permanece a aposta na transparência da linguagem, supondo clareza e objetividade. Rejeitando este pressuposto, não se trata aqui de discutir o campo da Didática propriamente dita, mas a configuração do discurso pedagógico contemporâneo na pesquisa participante específica.

A pesquisa em questão, intitulada A Leitura no Aperfeiçoamento do Ensino: uma proposta de pesquisa participante, foi inscrita no Programa de Apoio à Melhoria do Ensino em Escolas Públicas do Estado do Rio de Janeiro, financiado pela FAPERJ. Foi desenvolvida no Rio de Janeiro, mais precisamente na Sala de Leitura da Escola Municipal Argentina, em 2008. Compreendeu um conjunto de vinte encontros de leitura não compulsórios, com alunos do $4^{\circ}$ ano, com a presença da professora regente e da equipe de pesquisa, envolvendo pesquisadores e alunos de Mestrado e Doutorado em Educação e de Graduação em Pedagogia da Universidade do Estado do Rio de Janeiro.

Do ponto de vista do discurso pedagógico (DP), esta abordagem compreende o conjunto das práticas de linguagem desenvolvidas nas mais variadas situações de ensino e sobre o ensino, sendo as últimas enfatizadas neste texto, na medida em que a pretensão é sistematizar reflexões acerca daquele substantivo (ensino), cuja intencionalidade pode não remeter exatamente a prescrições, mas que também não deixa de incluir traduções de alguma forma de dever ser (Barreto, 2009).

Nos termos da formulação de Orlandi (1987), o DP tende a ser autoritário, na medida da sua circularidade, como "[...] um dizer institucionalizado, sobre as coisas, que se garante, garantindo a instituição em que se origina e para a qual tende: a escola" (Orlandi, 1987, p. 28). Sob a rubrica da cientificidade, dissimula-se como transmissor de informações. Marcado pela assimetria, sua reversibilidade pode tender a zero, sendo prerrogativa de um agente único: aquele que tem o poder de dizer e de apontar, através da metalinguagem, para o obscurecimento do referente, na medida mesma da apropriação do cientista pelo professor.

De um lado, a combinação de intencionalidade e assimetria pode significar o estancamento da reversibilidade, não cedendo a palavra e 
reduzindo os interlocutores a meros ouvintes. De outro, é a própria intencionalidade que pode sustentar a relativização da assimetria. Como afirma a referida autora, a possibilidade de romper com a circularidade do DP está na crítica, como deslocamento para o discurso polêmico.

A menção à crítica acerca das práticas de leitura e produção textual na escola hoje, que será objeto de análise na próxima seção, é crucial neste ponto para afastar a suposição de que o DP possa ser pensado como um bloco monolítico. Ao contrário, é uma arena em que diferentes tendências estão em luta por hegemonia. Em síntese, ainda que guarde semelhanças de raiz, o DP é plural, não apenas por envolver diferentes conteúdos de ensino, mas também por expressar tendências díspares nos modos de aproximação das questões educacionais e em todo o processo do seu encaminhamento.

\section{Em Foco: o ensino da leitura}

A escolha deste foco está diretamente ligada a três aspectos constitutivos do ensino de leitura: (1) o lugar contraditório por ela ocupado historicamente no conjunto das questões educacionais; (2) o desafio de superar o que se pode chamar de modelo escolar de leitura (Chartier; Hébrard, 1995); e (3) as possibilidades inscritas nas novas condições de produção e circulação viabilizadas pelas TIC.

O primeiro aspecto diz respeito a uma espécie de acordo tácito, no qual o ensino da leitura, como habilidade linguística, seria da competência exclusiva do professor de língua materna (Giroux, 1988), não tendo dimensão curricular reconhecida. Entretanto, a ausência de domínio desta mesma habilidade interfere na aprendizagem dos mais diversos conteúdos e, no limite, pode vir a ser identificada à principal causa do fracasso escolar.

O segundo aspecto aponta para o desafio maior, que é a superação de um modelo escolar de leitura, caracterizado por Chartier e Hébrard (1995): centrado na interpretação como desvelamento do sentido correto, em perspectiva originalmente religiosa que ao Estado interessou manter. Seu pressuposto básico é o da presença de um sentido único, verdadeiro, a ser atestado por um intérprete autorizado.

Para dimensionar este desafio, citamos aqui o discurso de uma aluna no primeiro encontro de leitura. Após assistir a um curta-metragem tecido por imagens em sucessão com fundo musical, mas sem a linguagem verbal previsível, a não ser pelas duas palavras em inglês fundidas no título, bem no início da discussão a respeito, uma aluna formula muito timidamente a pergunta: "Mas, eu posso falar mesmo o que é que eu acho?"5.

Depois de ser estimulada a registrar uma eventual transgressão, prosseguiu: "Este filme não parece coisa de escola". Não parecia porque a linguagem verbal não era central e porque a polissemia não seria

576 Educação \& Realidade, Porto Alegre, v. 40, n. 2, p. 573-590, abr./jun. 2015. 
contida. Autorizada a romper com o enredo autoritário, poderia falar do que captou naquele texto. Só então ela e os outros falaram.

Recuperando a formulação de Orlandi (1987; Orlandi, 1988), o DP autoritário tende a não admitir leituras, no plural. Centrado por vezes na mera decodificação, pode estar satisfeito com identificação do que está explícito. Quando ultrapassa este patamar, tende a cair na armadilha ideológica da interpretação como desvelamento: um só sentido, uma única resposta correta. Até mesmo em relação a obras literárias, ainda se ouvem perguntas como a que diz respeito à personagem Capitu, de Machado de Assis (1994), em Dom Casmurro: afinal, ela traiu Bentinho ou não?

Finalmente, o terceiro aspecto - as possibilidades inscritas nas novas condições de produção e circulação viabilizadas pelas TIC - pode ser sintetizado na fala de outro aluno: "Texto não é mais sopa de letrinhas". Isto é, os textos contemporâneos articulam linguagens. Palavra, som e imagem fazem parte da maioria dos textos veiculados em diferentes mídias e suportes. A linguagem verbal não é mais exclusiva, ainda que possa permanecer central, sobredeterminando as outras linguagens (Orlandi, 1995), matérias significantes (Kristeva, 1988), ou, ainda, em perspectiva linguística ortodoxa, outros materiais semióticos (Fairclough, 2001).

Um exemplo emblemático pode ser a configuração textual mais comum aos outdoors: imagens gigantescas e frases sintéticas que lhes constrangem os sentidos possíveis, demarcando os desejáveis. A polissemia da imagem, se mantida aberta, poderia capturar o olhar para além do produto anunciado, desenhando pontos de fuga incompatíveis com a intenção mercadológica. Logo, sua produção não pode ser pensada apenas em termos técnicos, mas da intencionalidade que a sustenta, já que os textos são produzidos para serem lidos. A leitura é a sua destinação.

Entretanto, retomando o que foi dito acerca do segundo aspecto, as mudanças das configurações textuais, como no exemplo dos outdoors, que articulam imagem e palavra, nem sempre têm sido acompanhadas de considerações relativas à sua leitura. Isto é, na escola a leitura ainda tende a ficar centrada na palavra escrita. É como se os textos mudassem, mas pudessem permanecer os gestos de leitura no espaço escolar. Ou, pior ainda, é como se as novas configurações textuais, na medida em que tecidas não apenas por palavras, se tornassem mais fáceis e até óbvias. Como se as imagens, por exemplo, apenas ilustrassem o que está escrito (Barreto, 2002).

Não cabe mais às imagens o lugar de mera ilustração da escrita, como demonstrou Chartier (1998). O autor, ao analisar a aventura do livro no percurso do leitor ao navegador, dá conta da história da relação centro-margens, da disjunção de texto escrito e imagem, tanto do ponto de vista do controle religioso e estatal dos gestos de leitura, quan-

Educação \& Realidade, Porto Alegre, v. 40, n. 2, p. 573-590, abr./jun. 2015. 
to das condições técnicas da sua produção. Afirma que não apenas o Verbo sempre foi central, como, para imprimir caracteres tipográficos e gravuras em cobre, eram necessárias prensas diferentes, duas oficinas, duas profissões e duas competências. Não havia junção possível. Assim, até o século XIX, a imagem permaneceu, até mesmo literalmente, "situada à margem do texto" (Chartier, 1998, p. 10). Hoje, as condições técnicas de produção favorecem textos que articulam palavra, som e imagem. São os textos multimidiáticos (Guimarães, 2010).

Do ponto de vista técnico, multimídia é a tecnologia caracterizada por permitir a combinação, em um mesmo programa e em formato digital, de mídias diversas: textos verbais, imagens, sons, etc., em movimento. Do ponto de vista discursivo, permite a coexistência de distintas ordens de materialidade em um mesmo espaço. Entretanto, a presença de textos multimidiáticos, cada vez mais favorecida pela proliferação de suportes que os viabilizam, por vezes tem sido encarada a partir de uma simplificação de raiz: como se fosse sempre uma justaposição de matérias significantes, como se elas não se articulassem de diferentes modos na produção dos sentidos (Barreto, 2012).

Para superar esta simplificação, temos insistido que é preciso analisar as danças das linguagens nos textos, nas suas múltiplas possibilidades. Pensando para além da coexistência, buscamos analisar modos básicos de articulação de palavras e imagens: (1) a articulação por convergência, feita pelo reforçamento mútuo de sentidos através das linguagens utilizadas; (2) a divergência apontando para sentidos diversos, em que cada uma das linguagens pode propiciar uma chave específica de leitura; e (3) a contiguidade, como proximidade no espaço e/ou no tempo de elementos textuais diversos, promovendo sequências inusitadas na sucessão de palavras e imagens (Barreto, 2002; Guimarães, 2010).

Pelo já dito acerca da tendência a manter um modelo escolar de leitura, a articulação por convergência, mais próxima dos textos chamados didáticos porque simplificados, tende a estar mais presente por não causar desconforto em relação ao gesto interpretativo: à confirmação de um sentido único que, saturando o imaginário, parece mesmo ser o necessário, correto (Orlandi, 1992). Por exemplo, em textos de publicidade de destinos turísticos, tanto as palavras quanto as imagens reforçam o ideal paradisíaco, de modo a favorecer a venda de pacotes.

Os textos articulados por divergência se distanciam da espécie de zona de conforto que compreende as supostas certezas. Na medida em que palavras e imagens apontam em direções diferentes, a leitura correta não escapa a algum modo de relativização determinado pela chave escolhida ou, ainda, pela compreensão do duplo ponto de entrada. É o que se pode verificar, por exemplo, no curta-metragem Ilha das Flores ${ }^{6}$, especialmente quando a definição de água (uma substância inodora, insípida e incolor) é apresentada verbalmente e a imagem é a de água barrenta, quase marrom. 
As articulações por contiguidade implicam desafios ainda maiores, extrapolando o nível das frases para remeter às relações entre elas no tempo e/ou no espaço. No mesmo curta-metragem mencionado acima, a citação das produções humanas possibilitadas pela conjugação do tele-encéfalo altamente desenvolvido e do polegar opositor culmina com a imagem do cogumelo formado pela bomba atômica, imediatamente seguida pela imagem de um tomate sendo colhido e pela expressão: cultivar tomates.

Em síntese, os textos tecidos por múltiplas linguagens implicam novos desafios, marcados nesta seção pela adjetivação: leitura crítica. Com ela pretendemos sublinhar a possibilidade de ruptura em relação ao denominado modelo escolar e ao DP predominantemente autoritário. Falar de leituras, no plural, não deixa de ser um passo na sua direção, mas pode remeter apenas a um relativismo satisfeito de si mesmo. No horizonte histórico, há leituras possíveis, feitas de lugares e posições diferentes, demandando o esforço teórico da compreensão e implicando o redimensionamento das condições da sua produção. Nas palavras de Orlandi, (1987, p. 86); “[...] ser crítico, tanto pelo lado do locutor quanto do ouvinte, é questionar as condições de produção desses discursos"; e "[...] a postura crítica está em não se absolutizar essa perspectiva pela qual se observa o fato” (Orlandi, 1988, p. 35).

Considerando a tipologia discursiva elaborada por Orlandi (1987), baseada na tensão entre paráfrase e polissemia, é fundamental dimensionar as relações entre os sujeitos interlocutores e destes com o objeto da interlocução. A partir destes dois parâmetros, a autora sistematiza três tendências: ao discurso autoritário, ao polêmico e ao lúdico.

A assimetria constitutiva do DP tende a remeter à presença de um agente que pode estancar a reversibilidade por não ceder a palavra, reduzindo interlocutores a ouvintes, falando sobre as coisas, mais do que das coisas mesmas, promovendo formas de elogio da paráfrase através do formalismo vazio. Exemplos desta tendência são numerosos. Aqui destacamos o de uma sala de aula em que a professora ditava aos alunos a definição de retângulo. Eles copiavam nos seus cadernos retangulares, tentavam reproduzir o desenho feito no quadro retangular da sala retangular etc. Em nenhum momento a presença de tantos retângulos pareceu ter sido sequer cogitada.

A relativização da assimetria aponta para a possibilidade de considerar os objetos de que se fala, ultrapassando a sua definição já formalizada, falando deles a partir dos diferentes lugares sociais ocupados. Lembrando que tomar a palavra é um ato social com todas as suas implicações, este movimento também é caracterizado pela tentativa de imprimir-lhe uma direção a partir das perspectivas adotadas. Por exemplo, ao tratar do tema da ocupação das comunidades pela polícia, encaminhamentos divergentes tendem a ser determinados pelas experiências vividas pelos interlocutores, dentro e/ou fora desses espaços ocupados. Dito 
de outra maneira, o exercício crítico é um desafio a lidar com a alteridade, que passa por tentar ver do lugar do outro.

Enquanto no discurso polêmico predomina a tentativa de expor argumentos que justifiquem as diferentes percepções/leituras, no discurso lúdico não há a pretensão dos interlocutores de dominar o objeto ou tema. Eles simplesmente expõem à sua presença, numa relação simétrica, real ou pactuada, que favorece a expansão da polissemia, apontando para deslocamentos em relação aos dizeres sedimentados. As condições da sua produção supõem espaços mais livres, como nas conversas de botequim, ou pelo menos não tão regulados como os escolares. Entretanto, se não é viável exercitá-lo por inteiro na escola, também não há porque negar alternativas de aproximação possíveis como, por exemplo, em se tratando da leitura de textos poéticos (Guimarães, 2002).

A consideração da tipologia discursiva acima tem, aqui, a intenção de situar as questões relativas aos textos que circulam na escola e aos modos pelos quais eles têm sido trabalhados. Nas palavras de Kramer (2001, p. 111), “[...] a escola brasileira tem alijado do ensino da língua aqueles que fazem dela material de produção viva”. Assim, a tendência autoritária tem tido inegáveis consequências na redução dos textos escolares aos didáticos e na leitura centrada na paráfrase, como se pode verificar a partir das duas falas dos alunos registradas no início desta seção: “[...] este filme não parece coisa de escola"; e "[...] mas, eu posso falar mesmo o que é que eu acho?".

Nos mais diversos espaços, os leitores são expostos cotidianamente a uma miríade de textos multimidiáticos. Na escola, como espaço de trabalho simbólico sistemático, é preciso favorecer a construção de outra história de leituras pelo sujeito-leitor, considerando não apenas os textos destinados à aquisição de conteúdos específicos, mas a multiplicidade de configurações que circulam na sociedade. Portanto, no sentido de favorecer a construção dessa história de leituras pelo sujeito-leitor, a seguir são analisadas algumas condições da sua produção em situação concreta de ensino.

\section{Uma Prática de Pesquisa}

A pesquisa que sustenta esta produção integra o movimento de buscar aprofundar o diálogo entre a universidade e a escola pública, encaminhando questões relativas às relações entre produções textuais e leituras na contemporaneidade, com vistas e superar o distanciamento que lhes parece imposto: a tendência de que, apesar da inegável mudança nos textos, os gestos de leitura permaneçam relacionados ao modelo escolar e ao discurso pedagógico caracterizado na primeira seção deste artigo $^{7}$.

Visando a caracterizar melhor o contexto de realização da pesquisa, é relevante a análise das políticas que têm sustentado a concepção do espaço das Salas de Leitura. Iniciado em 1985, o programa foi 
consolidado como alternativa aos espaços de Multimeios e Bibliotecas Escolares existentes, buscando ressignificar e redimensionar as práticas até então desenvolvidas. Coordenado pelo setor de Mídia e Educação, visava a favorecer o acesso aos diferentes meios de informação, comunicação, no desenvolvimento de um trabalho que privilegiasse a leitura crítica dos mesmos (Deco, 2012) . $^{8}$

Cabe ressaltar que no ano de 2009, um ano após a pesquisa desenvolvida, a SME-RJ sofreria mudanças produzidas na gestão Claudia Costin, quando os baixos índices de rendimento dos alunos na Prova Brasil passaram a sustentar diversos programas. Um deles, Rio, uma Cidade de Leitores, acabou por afetar diretamente o espaço da Sala de Leitura, com a ênfase deslocada para os processos de empréstimo e de treinamento para responder às provas acerca de textos literários nelas cobrados, especialmente a partir de 2011, pela adição do projeto Jovens Leitores.

Assim, quando da realização da pesquisa em questão, a Sala de Leitura oferecia condições favoráveis a novas práticas nas escolas municipais, como espaço privilegiado que reunia: (1) as TIC disponíveis na escola; e (2) alunos de diferentes séries e turmas, em atividades não obrigatórias, sem a pressão representada pela avaliação formal, expressa na atribuição de notas ou conceitos para aprovação/reprovação.

Retomando a caracterização da pesquisa, do ponto de vista dos pesquisadores envolvidos, o grupo era composto pelas autoras, na coordenação, doutorandos e mestrandos filiados ao grupo de pesquisa, uma das professoras da Sala de Leitura como bolsista de Apoio Técnico, e alunos de graduação inscritos em Pesquisa e Prática Pedagógica, disciplina do Curso de Pedagogia da Faculdade de Educação da UERJ, com duração de seis semestres, em horário fixo que correspondia a uma manhã por semana, favorecendo a pesquisa do ensino e o ensino da pesquisa.

Na prática, nem todas as condições previstas se confirmaram: (1) o trabalho acabou restrito a alunos de uma única turma do $4^{\circ}$ ano; e (2) as TIC não estavam tão disponíveis quanto pensávamos, mormente em se tratando de conexão à internet. O dito Laboratório de Informática ficava ao lado da Sala de Leitura e era o espaço mais desejado pelos alunos. Composto por mais de dez computadores, sugeria uma promessa a não ser cumprida, na medida em que: (1) a ligação em rede se resumia à impressora e a uma frágil conexão à internet em horários muito limitados; e (2) os recursos e as configurações das máquinas apresentam variações que dificultavam o trabalho coletivo. Assim, por exemplo, para que imagens pudessem ser exibidas nos diferentes monitores, era preciso inseri-las previamente em cada máquina (algumas sequer tinham multimídia), por pen drive ou CD.

O redimensionamento do trabalho, baseado na reflexão conjunta, foi determinante para que a ausência de acesso fácil aos textos mul- 
timidiáticos não remetesse apenas a restrições expressas em forma de lamentação e/ou desistência. Esta reflexão foi importante para a superação da perspectiva simplista e hegemônica de que, se as TIC estivessem disponíveis, as questões relativas a ensino-aprendizagem estariam resolvidas.

Para dimensionar o trabalho realizado, segue uma tentativa de síntese de alguns dos vinte encontros de leitura, pensados em função de duas dimensões (configurações textuais e temas), considerando idade e nível de escolaridade.

No primeiro encontro de leitura, cujo tema era diferentes sujeitos, linguagens e sentidos, o trabalho foi introduzido pelo filme de animação Balablok, mencionado na primeira seção. Os objetivos eram: (1) mostrar a ruptura com os parâmetros da linguagem verbal escrita (o texto continha apenas as duas palavras em inglês fundidas no título), como base para todo o processo de discussão dos sentidos produzidos por diferentes linguagens articuladas; (2) marcar a possibilidade de diferentes leituras dos textos (ruptura com o sentido supostamente único), nas suas relações com os lugares e posições de onde elas são feitas; e (3) valorizar as interações baseadas no respeito às diferenças.

Superado o estranhamento inicial, os alunos se mostraram empolgados com a possibilidade de ler e expressar o que leram, sem as amarras da resposta supostamente correta e da linguagem verbal.

No segundo encontro, já considerando que não são apenas diferenças em jogo, decidimos abordar mais claramente as desigualdades. Para tanto, escolhemos um poema de Manoel de Barros (2007), acompanhado de imagem articulada por convergência9:

$$
\begin{aligned}
& \text { Sentado sobre uma pedra } \\
& \text { no mais alto do rochedo } \\
& \text { aquele gavião } \\
& \text { se achava principal: } \\
& \text { mais principal do que todos. } \\
& \text { Tem gente assim. }
\end{aligned}
$$

A leitura feita em duplas ou trios reunidos em torno de cinco computadores pareceu muito estimulante. Todos retornaram a eles após a discussão para a produção textual. Alguns disseram que era a primeira vez que eles escreviam alguma coisa no computador. Houve dificuldades para localizar as letras no teclado, o que não diminuiu o interesse em realizar a tarefa proposta, uma vez que todos, de forma mais ou menos elaborada, completaram o trabalho.

Quanto à discussão, o objetivo central era extrapolar o que estava posto. E eles chegaram a verbalizar uma alternativa para os passarinhos enfrentarem a desigualdade: unirem-se para enfrentar o gavião.

No encontro anterior, a dinâmica desenvolvida a partir do poema de Manoel de Barros suscitou a demarcação do lugar ocupado por passarinhos e gaviões entre os próprios colegas da turma. Este fato desen- 
cadeou o planejamento de trabalho para o terceiro encontro, baseado em algumas situações presentes no livro O Frio Pode Ser Quente? ${ }^{10}$, de modo a favorecer a compreensão de que as coisas podem ter diferentes definições de acordo com a maneira como são vistas pelos sujeitos, a partir de lugares sociais diversos. Foram apresentadas três situações nas quais conceitos relacionados a quantidade, comprimento, volume e tempo podem assumir diferentes sentidos em função das perspectivas assumidas.

A discussão foi muito rica e terminou sob os aplausos dos alunos.

No quarto encontro, para consolidar a noção de perspectiva, elegemos uma configuração textual que tende a ser bastante utilizada na escola: a fábula. Como esta utilização não pode ser dissociada da "moral" ratificadora de um sentido supostamente único, lançamos mão de uma das Fábulas Fabulosas, de Millôr Fernandes: A Barata e o Rato ${ }^{11}$.

Os alunos, organizados em pequenos grupos, foram solicitados a colar frases do texto papel A3 dividido ao meio: coisas boas e ruins, esclarecendo para quem?, já que barata e rato assumem posições diferentes das esperadas dos seres humanos. Um dos grupos colou uma das frases no meio do papel, justificando que ela não expressava algo bom ou ruim. De um lado, sugeriam o afastamento de uma possível leitura maniqueísta. De outro, considerando as dificuldades de expressar os pontos de vista da barata e do rato, verificamos que seria necessário retomar a compreensão do texto no encontro seguinte.

No quinto encontro, não apenas retomamos o texto anterior, mas, para consolidar as noções até então trabalhadas, selecionamos imagens usualmente encontradas na abordagem da teoria da Gestalt, que pudessem ser um mote para trabalhar as diferentes perspectivas. Nos computadores, os alunos eram solicitados a expressar o que viam e a ouvir o que era visto pelos demais. Buscamos a duplicidade intencional da imagem, na sua relação com o foco assumido, assim como pares que envolviam perspectivas diversas, como no caso do sapo e do cavalo ${ }^{12}$, par de imagens preferido por todos.

Mesmo parecendo afastada a noção de uma leitura única possível, no sexto encontro optamos por combinar as duas noções: a de perspectivas e a de representações, a partir do livro infantil Zoom, de Istvan Banyai ${ }^{13}$. O livro é constituído apenas de imagens. A sequência dá a impressão de que o leitor se afasta rapidamente de cada página, mostrando que estas imagens são representações da realidade contidas em meios de comunicação, como revista, televisão etc. Do nível macro para o micro e vice versa, os alunos tomaram contato com o processo de edição constitutivo das imagens e a elas retornaram na representação do "efeito de aproximar e afastar" da visão.

Deste encontro até o décimo primeiro as abordagens foram aprofundadas. Neste contexto, no décimo segundo encontro, achamos possível abordar tema complexo: as condições de produção dos sentidos.

Educação \& Realidade, Porto Alegre, v. 40, n. 2, p. 573-590, abr./jun. 2015. 
O objetivo era abordar as diferenças estruturais de duas configurações textuais (anúncios classificados de casas) e uma canção ( $A$ Casa, de Vinícius de Morais, gravada por Toquinho), nas suas relações com denotação e conotação, ainda que estes termos não fossem usados. Supúnhamos poder marcar pelo menos dois sentidos de casa: como imóvel objetivamente anunciado para venda e como espaço poético, mais próximo de lar, como negação da objetividade suposta.

O que não supusemos foi a intervenção de um programa de TV (Caldeirão do Huck, especialmente através do quadro Lar Doce Lar), tendo como tema outra versão da música, em ritmo mais acelerado, gravada pelo grupo Capital Inicial. Além disso, sob o patrocínio de lojas de construção e de decoração, a proposta no programa de TV era a de mudar a vida de toda a família com a reforma do imóvel.

Em outras palavras, a polissemia do referente "casa" parecia comprometido. No trabalho de corte e colagem proposto, prevaleceu a casa como uma espécie de sonho maior de consumo, que incluía itens como celulares, purificadores de água, etc. Era, sem dúvida, uma abordagem a retomar.

Procuramos, então, abordar o mesmo em construções diferentes. Voltamos ao tema do encontro anterior, questionando se a música era a mesma e se estávamos falando da mesma coisa quando dizíamos casa. Tendo percorrido, no encontro anterior, o caminho das palavras para as imagens, a inversão foi assumida. A partir de cerca de 40 imagens, foi feita reflexão sobre a inscrição da casa no universo simbólico. Só então ocorreu a ampliação e outros sentidos puderam ser expressos: a variedade de casas existentes, o mar como a casa dos peixes, a jaula como a casa do leão no circo, o Maracanã como a casa dos times etc.

No décimo quarto encontro, para consolidar a ampliação dos sentidos circulantes, apresentamos o livro Casas, de Roseana Murray ${ }^{14}$, em que as variações do tema são apresentadas em forma de poesia. Foi desencadeado um processo de produção textual que ganhou contornos de produção poética possível, indo das palavras às imagens e vice-versa, contemplando casas reais e imaginárias.

No encontro seguinte o movimento foi o de tentar adivinhar quem os produziu, como se fossem escritores renomados, mas os poemas lidos eram deles próprios. Lido o primeiro, a autora olhou assustada e disse: “Acho que esta história é minha!". A partir daí, todos queriam participar, dar sua opinião sobre o poema do colega e ouvir o poema de sua autoria.

Nos encontros seguintes, a medida que os alunos iam produzindo os textos para o livro Casas Poéticas, não previsto no planejamento inicial, íamos abordando novas temáticas.

Como havia entre os pesquisadores o mal-estar em relação ao consumismo exacerbado ali presente, em um dos encontros seguintes, questionamos se seria esse o sentido maior da vida. Planejamos a exi- 
bição do longa-metragem de animação Robôs ${ }^{15}$, que transita entre dois slogans: (1) Não importa do que você seja feito, você pode brilhar!; e (2) Para que ser você mesmo se você pode ser novo?

Voltando ao tema do consumismo, a ideia de um dos encontros finais era a de produzirmos textos que geralmente só consumimos. Trabalhamos com três objetos: um celular, uma boneca de pano e um carrinho de madeira. Todos em ótimo estado, sem estarem na moda. O celular funcionava, mas não tinha muitas das funções disponíveis nos modelos mais recentes e caros. A boneca e o carrinho eram brinquedos que pareciam distantes do universo infantil contemporâneo. A tarefa era escolher um objeto e produzir peça publicitária para convencer o público alvo a comprá-lo. Era um deslocamento intencional: experimentar o outro lado. Terminadas as apresentações e a discussão entusiástica, houve uma reflexão acerca do movimento de jogar fora ou colocar de lado o que já não é mais tão novo, bem como das suas consequências na vida das pessoas.

$\mathrm{O}$ vigésimo foi o encontro final e hora da festa. Apresentamos aos alunos a página da pesquisa na internet ${ }^{16} \mathrm{e}$ muitos quiseram inaugurar o link Fale conosco. Foi feito o lançamento do livro Casas Poéticas, coletivo e caseiro, feito de cópias espiraladas, com um exemplar para cada um e, ainda, com direito a festa, com salgadinhos e doces. Alguns alunos quiseram ler suas poesias, alegres se vendo como os autores que escreveram e desenharam as leituras feitas. Entre o livro impresso e a internet, em meio às múltiplas linguagens, o desejo maior expresso pelo grupo de pesquisa era (e continua sendo) que todos os sujeitos autores desta trajetória estejam cada vez mais conectados ao movimento dos sentidos.

Algumas observações podem favorecer a assim chamada avaliação dos resultados. Uma foi a presença sistemática da narrativa, configuração textual mais propícia à captação dos vários sentidos naquela faixa etária e nível de escolaridade ( $4^{\circ}$ ano), ressaltados pela articulação de palavras e imagens. Outra foi a tendência de conjugar leitura e produção textual, que resultou em um produto muito apreciado pelos alunos.

As leituras, sempre no plural, parecem ter afastado a hesitação diante das perguntas voltadas para a compreensão dos textos. Todos os participantes foram sendo surpreendidos pelos efeitos produzidos por textos que não pareciam coisa de escola, naquelas condições: com os alunos podendo de fato expressar o que achavam.

Dizendo de outra maneira, a principal contribuição da pesquisa é um conjunto de possibilidades para a formação docente, incluindo a recontextualização da leitura, remetendo ao trabalho sistemático com os novos textos disponíveis: um movimento que se afasta da decodificação e da interpretação, em busca da compreensão dos diferentes sentidos produzidos. 


\section{Para Novas Práticas}

Em momento algum da trajetória relatada, houve qualquer pretensão de produzir um modelo de abordagem, o que, inclusive, colocaria em xeque a coerência da produção. Todo o tempo, nosso movimento foi o de construir e socializar uma prática concreta e situada, fundada em abordagem discursiva do ensino da leitura, com seus ganhos e seus limites, em seu curso e seus percalços, de modo a favorecer a produção de novas práticas, pensadas em função das condições específicas de cada contexto.

Em outras palavras, a proposta é de recontextualização (Bernstein, 1996, p. 259). A rigor, na medida em que o próprio pedagógico é caracterizado pelo autor como "[...] um princípio para apropriar outros discursos e colocá-los numa relação mútua especial, com vistas à sua transmissão e aquisição seletivas”, estamos tratando de uma cadeia de recontextualizações: de pressupostos e conceitos da área dos estudos da linguagem, notadamente no que se refere à análise de discurso (Orlandi, 1987; Orlandi, 1988; Orlandi, 1992; Orlandi, 1995), para uma situação concreta de ensino da leitura, da reflexão acerca desta para outras aplicações possíveis etc.

Outras recontextualizações já houve, especialmente na região metropolitana do Rio de Janeiro, embora não sejam objeto de análise circunstanciada neste espaço. Foram produzidas em situações de Pesquisa e Estágio Supervisionado em salas de aula convencionais, portanto marcadas pela obrigatoriedade de atribuição de notas. Ainda que neste contexto seja mais complexo o trabalho de relativizar a assimetria e empreender o esforço teórico de compreender as leituras feitas, é possível afirmar que, também envolvendo os professores regentes das respectivas turmas, foram significativos os ganhos em termos da discussão acerca do discurso autoritário e detectados avanços em direção ao exercício crítico ${ }^{17}$.

Os pressupostos e conceitos acima referidos são os abordados na segunda seção deste artigo. Na tentativa de sistematizá-los, é fundamental começar sublinhando a relação entre textos e leituras, rejeitando a espécie de abismo entre eles, produzido pela noção de que a produção textual extrapola a escola e está cada vez mais complexa, enquanto permanece um modelo escolar de leitura. Nesta direção, o primeiro passo é a abordagem de textos significativos, rejeitando o formalismo estéril que, como tal, implica ausência de sentido. Como exemplo, parece oportuno citar a crítica veemente feita por Gribel (2000) às redações, escritas do ponto de vista de um aluno, que (ainda) tendem a ser propostas, em Minhas Férias, Pula um Linha, Parágrafo.

$\mathrm{O}$ afastamento do discurso autoritário exige a ruptura com a suposição de uma única leitura correta, aqui posta como o grande desafio. Também requer a análise das condições de produção históricas e situ- 
acionais das práticas de leitura. Não havendo uma fórmula aplicável a qualquer situação, é o mergulho na concretude de cada uma delas que permitirá inscrevê-la no eixo tempo-espaço e forjar novas possibilidades. Vale insistir no caráter processual da construção, conduzida por linhas de ação estabelecidas no planejamento e na avaliação constantes, sem definir de antemão o exato ponto de chegada.

No caso da pesquisa aqui relatada, exigiriam outros trabalhos de recontextualização: a presença de alunos de diferentes níveis e séries, as mudanças impostas à dinâmica das Salas de Leitura a partir de então etc. Nas próprias condições em que o trabalho foi desenvolvido, se o conhecimento das condições materiais de existência deles, em sua maioria moradores das favelas no entorno da escola, fez com que não estranhássemos a associação das casas grandes aos aposentados, haverá sempre desconhecimentos em relação aos sujeitos envolvidos nos processos.

Sem garantias quanto ao conjunto de ideias que poderiam nos parecer boas, precisávamos lidar com as que não dariam muito certo. Neste caso, a abordagem dos sentidos de casa implicou uma retomada que, por sua vez, acabou levando à produção (não prevista) do livro coletivo. A seleção e a organização dos textos tinham que estar abertas às questões suscitadas durante o percurso. Os alunos não leem apenas os textos propostos na/pela escola. Estão expostos a uma variedade de textos multimidiáticos e as suas leituras não podem ser relegadas a um segundo plano. Ademais, como afirma Orlandi (1988, p. 12): “[...] ler [...] é saber que o sentido pode ser outro”. Daí a definição discursiva de ideologia como hegemonia de sentido.

Em nome da coerência da proposta como um todo, é importante insistir que a trajetória empreendida não pretende ser $a$ resposta, mas uma alternativa produzida em situação concreta, cuja análise pode permitir a sua reposição em novos processos, como outras provas práticas. O que propomos é a formalização de propostas contra-hegemônicas sustentadas por trajetórias singulares que vão da prática à prática, pela via da elaboração teórica.

Finalmente, esta nossa insistência se contrapõe à apropriação dos textos multimidiáticos como objetos de aprendizagem, nos termos em que o faz o discurso das políticas educacionais vigentes. Argumentamos que não há como aperfeiçoar o ensino de qualquer conteúdo pelo esvaziamento do trabalho docente, negando a autonomia do professor, na perspectiva da substituição tecnológica e na lógica do primado dos objetos técnicos. Sem negar o fato que as TIC permitem a produção e a circulação de textos cada vez mais multimidiáticos, é fundamental desmontar a suposição de que textos prontos, mesmo que atraentes e passíveis de quase infinitas reutilizações, possam ser significativos para todos e deem conta das diferentes dimensões do processo de ensinar-aprender.

Educação \& Realidade, Porto Alegre, v. 40, n. 2, p. 573-590, abr./jun. 2015. 
Recebido em 30 de março de 2014 Aprovado em 04 de janeiro de 2015

\section{Notas}

1 Disponível em: <http://www.publicacoes.inep.gov.br/arquivos/\%7B1DB5E222A831-495A-B62D-E52C5F8062F9\%7D_MIOLO_EstadoConhec_n\%C2\%BA9_ Educa\%C3\%A7\%C3\%A3o\%20e\%20Tecnologia.pdf>. Acesso em: 27 mar. 2014.

2 Para citar apenas exemplos oficiais, cabe destacar os bancos do Ministério da Educação (MEC), disponível em: <www.objetoseducacionais2.mec.gov.br >; da Secretaria de Estado de Educação do Rio de Janeiro (SEEDUC), disponível em: $<$ www.conexaoprofessor.rj.gov.br/objetos.asp >; e da Secretaria Municipal do Rio de Janeiro (SME), disponível em: <www.educopedia.com.br/Index.aspx>.

3 Uma escolha lexical a ser sublinhada.

4 Acesso em: 13 dez. 2014.

5 Filme de animação Balablok, dirigido por Bretislav Pojar (1972), com 7 min e 27s. Disponível em: <http://www.nfb.ca/animation/objanim/en/films/film. php?film=\&_onfplr_sel=plr\&sort=title\&id=10784\&formats=default\&speeds $=$ default\&use_cc=no\&use_dv=no>.

6 Curta-metragem de Jorge Furtado, produzido e distribuído pela Casa de Cinema de Porto Alegre.

7 Relato circunstanciado está disponível em: <http:/www.educacaoecomunicacao.org>.

8 Disponível também em: <http://www.proped.pro.br/teses/teses_pdf/2010_1499-ME.pdf>.

9 Cantigas por um Passarinho à toa. Rio de Janeiro: Galerinha Record, 2007.

10 Livro infantil de Jandira Masur, editado pela Ática em 1991, lida com a noção de perspectiva e termina com: "Ver de um jeito agora e de outro jeito depois... Ou melhor ainda ver na mesma hora os dois" (p. 32).

11 Editado pela Nórdica, em 1997.

12 Disponível, entre outros sites, em: <http://coiizas.blogspot.com.br/2011/08/ ilusoes-de-otica.html>. Acesso em: 28 mar. 2014.

13 Edição da Brinque-Book, 1995.

14 Editado pela Formato (2004).

15 Dirigido por Chris Wedge e Carlos Saldanha.

16 Disponível em:<http://www.educacaoecomunicacao.org/leituras_na_escola/ index.html>.

17 É o caso das pesquisas: (1) Articulação de linguagens na TV e leitura na escola: a apropriação dos textos multimidiáticos nas práticas pedagógicas (2008-2011); e (2) Internet e escola: discursos em confronto? (2011-2014), ambas financiadas pela FAPERJ.

\section{Referências}

ANDRÉ, Marli Eliza Dalmazo Afonso de; OLIVEIRA, Maria Rita Neto Sales (Org.). Alternativas do Ensino de Didática. Campinas: Papirus, 1996.

588 Educação \& Realidade, Porto Alegre, v. 40, n. 2, p. 573-590, abr./jun. 2015. 
ASSIS, Machado de. Dom Casmurro. Rio de Janeiro: Nova Aguilar, 1994. BANYAI, Istvan. Zoom. São Paulo: Brinque-book, 1995.

BARRETO, Raquel Goulart. Formação de Professores, Tecnologias e Linguagens: mapeando novos e velhos (des)encontros. São Paulo: Loyola, 2002.

BARRETO, Raquel Goulart. Discursos, Tecnologias, Educação. Rio de Janeiro: EdUERJ, 2009.

BARRETO, Raquel Goulart. A Recontextualização das Tecnologias da Informação e da Comunicação na Formação e no Trabalho Docente. Educação \& Sociedade, Campinas, v. 33, n. 121, p. 985-1002, out./dez. 2012.

BARROS, Manoel de. Cantigas por um Passarinho à toa. Rio de Janeiro: Galerinha Record, 2007.

BERNSTEIN, Basil. A Estruturação do Discurso Pedagógico. Tradução de Tomaz Tadeu da Silva e Luís Fernando Gonçalves Pereira. Petrópolis: Vozes, 1996.

CHARTIER, Anne-Marie; HÉBRARD, Jean. Discursos Sobre a Leitura. Tradução de Osvaldo Biato e Sérgio Bath. 5. ed. Rio de Janeiro: Ática, 1995.

CHARTIER, Roger. A Aventura do Livro: do leitor ao navegador. Tradução de Reginaldo Carmello. São Paulo: UNESP, 1998.

COMENIUS. Didáctica Magna. Tradução de Ivone Castilho Benedetti. 3. ed. São Paulo: Martins Fontes, 2006.

DECO, Marta Patrícia Duarte de. A Leitura das Salas. 2012. 191 f. Dissertação (Mestrado em Educação) - Programa de Pós-Graduação em Educação, Faculdade de Educação, Universidade do Estado do Rio de Janeiro, Rio de Janeiro, 2012. FAIRCLOUGH, Norman. Discurso e Mudança Social. Tradução de Izabel Magalhães. Brasília: Editora UnB, 2001.

FERNANDES, Millôr. Fábulas Fabulosas. Rio de Janeiro: Nórdica, 1997.

GIROUX, Henry. Teachers as Intellectuals: toward a critical pedagogy of learning. Massachusetts: Bergin \& Garvey, 1988.

GRIBEL, Chistiane. Minhas Férias Pula uma Linha, Parágrafo. São Paulo: Salamandra, 2000.

GUIMARÃES, Glaucia. TV e Escola: discursos em confronto. 4. ed. São Paulo: Cortez, 2002.

GUIMARÃES, Glaucia. TV e Educação na Sociedade Multimidiática: o discurso sedutor em imagem, som e palavra. Rio de Janeiro: Quartet-FAPERJ, 2010.

ILHA das Flores. Direção: Jorge Furtado. Porto Alegre: Casa de Cinema de Porto Alegre. Brasil, 1989. 13 min.

KRAMER, Sônia. Leitura e Escrita como Experiência: notas sobre seu papel na formação. In: ZACCUR, Edwiges Guiomar dos Santos. A Magia da Linguagem. Rio de Janeiro: DP\&A, 2001. P. 57-71.

KRISTEVA, Julia. História da Linguagem. Tradução de Margarida Barahona. 3ed. Lisboa: Edições 70, 1988.

MASUR, Jandira. O Frio Pode Ser Quente? São Paulo: Ática, 1991.

MURRAY, Roseana. Casas. Rio de Janeiro: Formato Editorial, 1994.

ORLANDI, Eni Puccinelli. Efeitos do Verbal Sobre o Não-Verbal. Revista Rua, Campinas, Universidade Estadual de Campinas, v. 1, n. 1, p. 35-47, mar. 1995.

ORLANDI, Eni Puccinelli. A Linguagem e seu Funcionamento: as formas do discurso. Campinas: Pontes, 1987.

Educação \& Realidade, Porto Alegre, v. 40, n. 2, p. 573-590, abr./jun. 2015. 
ORLANDI, Eni Puccinelli. Discurso e Leitura. São Paulo: Cortez-UNICAMP, 1988.

ORLANDI, Eni Puccinelli. As Formas do Silêncio: no movimento dos sentidos. Campinas: Editora da UNICAMP, 1992.

ROBÔS. Direção: Chris Wedge; Carlos Saldanha. Los Angeles: Twentieth Century Fox, EUA, 2005, 90 min.

Raquel Goulart Barreto é graduada em Letras e doutora em Educação (UFRJ), docente do Programa de Pós-graduação em Educação (ProPEd) da UERJ. Procientista, líder do Grupo de Pesquisa Educação e Comunicação, e pesquisadora do CNPq.

E-mail:raquel@uol.com.br

Glaucia Campos Guimarães é docente do Programa de Pós-graduação em Educação, Processos Formativos e Desigualdades Sociais da Faculdade de Formação de Professores e Procientista na UERJ. É líder do Grupo de Pesquisa Linguagens, tecnologias e leituras na escola.

E-mail: glauguimaraes23@gmail.com 